\title{
O Ensino da Sexualidade nos Cursos Médicos: a Percepção de Estudantes do Piauí
}

\author{
The Teaching of Sexuality in Undergraduate \\ Medical Education: the Perception of Students \\ from Piauí
}

\author{
Andréa Cronemberger Rufinol \\ Alberto Pereira Madeiro \\ Manoel João Batista Castello Girão ${ }^{I I}$
}

PALAVRAS-CHAVE:
- Educação Médica;
- Sexualidade;
- Educação Sexual;
- Currículo;
- Estudantes de Medicina.

KEYWORDS:

- Undergraduate Medical Education;

- Sexuality;

- Sexual Education;

- Curriculum;

- Medical Students.

Recebido em: 13/07/2012

Reencaminhado em: 22/12/2012

Aprovado em: 26/02/2013

REVISTA BRASILEIRA DE EDUCAÇÃo MÉdica $1 7 8 \longdiv { 3 7 ( 2 ) : 1 7 8 - 1 8 5 ; 2 0 1 3 }$
${ }^{I}$ Universidade Estadual do Piauí, Teresina, PI, Brasil.

"I Universidade Federal de São Paulo, São Paulo, SP, Brasil.

\section{RESUMO}

Realizou-se estudo descritivo e transversal com 242 alunos matriculados no internato em medicina de duas universidades públicas e duas faculdades privadas em Teresina, Piauí. Foi aplicado questionário semiestruturado para conhecer como a sexualidade humana foi ensinada nos cursos médicos. A taxa de resposta ao questionário foi de 86,3\%. O ensino da sexualidade foi identificado por 95,2\% dos alunos em algum momento do curso. As disciplinas que mais falaram sobre o assunto foram: ginecologia (91,9\%), psiquiatria (55,3\%), psicologia médica (30,6\%) e urologia (24,1\%). A sexualidade foi tema de aula em apenas 8,4\% dos relatos, mas foi comentada em outras aulas, como: câncer (70,9\%), aborto (67,5\%), DST e HIV/Aids (67\%). Quando o docente falou sobre sexualidade, enfatizou as disfunções sexuais $(84,1 \%)$, com menor evidência para homossexualidade (50\%) e direitos sexuais e reprodutivos $(40,6 \%)$. Os alunos apontaram influências positivas do ensino da sexualidade na graduação (96,1\%). Esses dados indicam que a sexualidade foi ofertada com destaque para a discussão de aspectos biológicos e de doenças associadas à sexualidade, com menor ênfase na construção social do tema e orientação sexual.

\section{ABSTRACT}

We conducted a descriptive and cross-sectional study with 242 medical undergraduates at two public universities and two private colleges in Teresina, Piauí. A semi-structured questionnaire to understand how human sexuality was taught in medical courses was applied. The questionnaire response rate was $86.3 \%$. The teaching of sexuality was identified by $95.2 \%$ of students at some time during the course. Gynecology was the discipline that discussed sexuality the most (91.9\%), followed by Psychiatry (55.3\%), Medical Psychology (30.6\%) and Urology (24.1\%). Sexuality was cited as a specific topic in only $8.4 \%$ of the reports, but it was reported in classes about other topics such as cancer (70.9\%), abortion (67.5\%), STD and HIV/AIDS (67\%). In class, the teacher emphasized sexual dysfunctions $(84.1 \%)$, with less emphasis on homosexuality (50\%) and sexual and reproductive rights $(40.6 \%)$. Students indicated that there were positive influences of sexual education in undergraduate study (96.1\%). There was great emphasis on the discussion of biological aspects and diseases associated with sexuality, with less emphasis on the social construction of the theme and sexual orientation. 


\section{INTRODUÇÃO:}

Os conhecimentos relacionados ao tratamento de queixas sexuais abriram novas perspectivas de atuação médica na última década. Em anos recentes, um destaque especial tem sido dado aos avanços na descoberta de novas drogas para tratar as disfunções sexuais. Apesar da atualidade da medicina sexual, dificuldades em abordar e tratar as queixas sexuais dos indivíduos durante consulta de rotina são comumente relatadas em publicações nacionais e internacionais. ${ }^{1,2}$ No Brasil, inquéritos realizados com médicos mostraram que 50 a $72 \%$ de ginecologistas, urologistas, psiquiatras e clínicos gerais não investigavam de forma regular a saúde sexual dos pacientes. A justificativa mais usada para essa atitude foi a deficiência de conhecimentos em saúde sexual (15 a 28\%) que, por sua vez, levava à insegurança (49\%) para abordar e tratar as disfunções sexuais. ${ }^{3,4}$

A atuação médica em questões que envolvem a saúde sexual também se mostra limitada para o atendimento integral e humanizado em situações de violência sexual, aborto legal e saúde geral para lésbicas, gays, bissexuais, travestis e transexuais (LGBT). 5,6,7,8 A percepção dos profissionais de saúde sobre a própria atuação em situações de aborto legal foi observada em estudo realizado em uma maternidade pública no Rio de Janeiro, em 2008. Nessa pesquisa, os médicos relataram falhas na sua formação profissional para atuação em situações de aborto previsto em lei, o que acarretava a desvalorização do relato das mulheres atendidas e, consequentemente, uma má qualidade na assistência. A necessidade de profissionais de saúde capacitados para a atenção em saúde sexual, de forma mais igualitária e integral, é defendida por vários autores. 5,6,7,8

$\mathrm{O}$ aspecto multidimensional da saúde sexual e sua relação com direitos e justiça social é enfatizado há décadas pela Organização Mundial de Saúde (OMS) e pela Associação Mundial para a Saúde Sexual (WAS). Essas entidades afirmam que a promoção da saúde sexual envolve a implementação de ações que contemplem toda a abrangência da sexualidade humana. Dessa forma, devem ser incluídos nas ações de promoção da saúde sexual desde aspectos de prevenção e tratamento de problemas sexuais, como também a valorização dos direitos sexuais, que incluem prazer, igualdade de gênero e acesso à educação sexual..$^{9,10}$

O papel central da sexualidade na saúde global dos indivíduos justifica o estímulo à educação sexual para profissionais de saúde. Através de documentos técnicos, a WAS reforça a necessidade de habilitar educadores, profissionais de saúde e estudantes para a abrangência da atuação em saúde sexual. ${ }^{10}$ Nesse sentido, as escolas médicas mundiais têm demonstrado interesse crescente em reavaliar seus currículos quanto ao

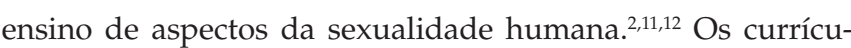
los médicos costumam oferecer uma visão reducionista da sexualidade. Há, com frequência, a valorização dos aspectos biológicos em detrimento daqueles relacionados à construção social da sexualidade humana e sua associação com a saúde. ${ }^{13}$ Muitas vezes, os estudantes são treinados apenas para coletar a história sexual dos pacientes, mas não desenvolvem habilidades para o atendimento que promova a saúde sexual $1^{2,11,12}$

A promoção da saúde sexual depende da qualidade da formação profissional em toda a amplitude de aspectos que envolvem a sexualidade. Há evidências de que a formação profissional deficiente em sexualidade afeta a capacitação para a assistência de qualidade..$^{8,14,15,16}$ Uma pesquisa qualitativa realizada em um hospital universitário de Ribeirão Preto identificou no discurso de médicos e estudantes de medicina o despreparo para o atendimento em situações que envolvem direitos reprodutivos, violência sexual e de gênero. Esses profissionais relataram a ausência de tais temas durante a sua formação médica, inclusive nos currículos. ${ }^{8}$

No Brasil, a formação dos estudantes de medicina para a assistência integral em saúde sexual é pouco conhecida. Há escassez de estudos empíricos sobre o ensino da sexualidade humana nos currículos médicos, com desconhecimento a respeito de como a sexualidade é ensinada, quais conteúdos são trabalhados e como são ofertados. Dessa maneira, este artigo tem o objetivo de conhecer como os alunos dos cursos de medicina descrevem o ensino da sexualidade humana durante a graduação, tendo o estado do Piauí como estudo de caso. A percepção dos estudantes piauienses sobre o ensino da sexualidade na graduação será utilizada para a reflexão sobre a formação médica relacionada à promoção da saúde sexual da população.

\section{CASUÍSTICA E MÉTODOS}

Trata-se de um estudo descritivo e transversal entre alunos do internato dos cursos de medicina do Piauí, desenvolvido entre junho e dezembro de 2010. Todos os 242 alunos matriculados no internato dos quatro cursos médicos existentes no estado foram convidados a participar da pesquisa. Desse total, 112 (46,3\%) estudantes eram de escolas públicas e 130 (53,7\%), de escolas privadas. As escolas públicas foram nomeadas como escolas 1 e 2 e tinham, respectivamente, 63 (26\%) e 49 (20,3\%) estudantes no internato. As escolas privadas, por sua vez chamadas de escolas 3 e 4, tinham $42(17,3 \%)$ e 88 (36,4\%) estudantes nesse período específico. A escolha pelos alunos do $5^{\circ} \mathrm{e}$ $6^{\circ}$ ano se deu devido ao fato de que, a essa altura do curso, eles já tiveram a oportunidade de contato com temas relacionados à sexualidade. 
Todos os alunos do internato foram contactados pessoalmente e, a cada um deles, foi explicada a pesquisa e oferecido o Termo de Consentimento Livre e Esclarecido. Após a aceitação deste, um instrumento de pesquisa impresso foi entregue aos alunos. $\mathrm{O}$ instrumento era composto por um questionário semiestruturado, com perguntas abertas e fechadas, a respeito de como a sexualidade humana foi ofertada durante o curso médico. Os questionários foram preenchidos pelos próprios alunos.

O questionário foi dividido em quatro tópicos. No primeiro, fez-se perguntas sobre a instituição de ensino do aluno, a fim de caracterizá-la. No segundo, questionou-se se o tema sexualidade foi oferecido em alguma disciplina do curso, a carga horária, o tipo de atividades didáticas desenvolvidas, além das aulas em que o tema foi inserido e que aspectos da sexualidade foram incluídos. Esse tópico teve como objetivo conhecer o ensino da sexualidade nas escolas médicas piauienses. No terceiro, colheu-se informações sobre os docentes e suas atitudes ao lidar com assuntos relacionados à sexualidade, a fim de conhecer os docentes que abordam a sexualidade na percepção discente. Por fim, o quarto tópico perguntou a opinião dos alunos sobre a relevância do ensino da sexualidade na graduação. Com esse tópico, pretendeu-se conhecer a importância conferida à sexualidade pelos alunos participantes do estudo.

Os temas, ou aspectos da sexualidade, escolhidos para compor o segundo tópico do questionário foram selecionados para abranger a amplitude dos aspectos da sexualidade humana, além daqueles considerados prioritários para a promoção da saúde sexual. Essa informação foi adquirida através de pesquisa no Documento Técnico e Declaração da Saúde Sexual para o Milênio da Organização Mundial para a Saúde Sexual (WAS). Além dessa fonte, foram pesquisados os aspectos da sexualidade em livros especializados no assunto. ${ }^{10,17,18}$

Os dados foram analisados através de estatística descritiva para obtenção de distribuição de frequência, com o uso do programa Excel 2010. Para a construção do banco de dados, foram utilizados 209 de 212 questionários respondidos. A duplicidade de resposta a questões com alternativa única invalidou 3 questionários, que foram desconsiderados. O número de alunos que respondeu o questionário variou a cada pergunta realizada. Sendo assim, o cálculo da distribuição de frequência foi realizado considerando somente o número de alunos que respondeu às questões específicas.

Os questionários não permitiram a identificação dos alunos participantes. As IES foram identificadas somente durante a coleta de dados. Durante a transferência das informações para a planilha de resultados, as IES foram codificadas e sua identificação nominal foi suprimida da tabulação final. A pesquisa foi realizada após aprovação pelo Comitê de Ética em Pesquisa do Instituto Camilo Filho - PI (CAAE 1379.0.000.044-10).

\section{RESULTADOS}

\section{Características da oferta de sexualidade \\ Disciplinas Envolvidas}

A taxa de resposta ao questionário foi de 86,3\% (209/242 alunos), sendo maior nas escolas médicas privadas (126/96,9\%) do que nas públicas $(83 / 74,1 \%)$. O ensino da sexualidade foi identificado por 199 (95,2\%) alunos em algum momento do curso, embora 194 (97,5\%) deles tenham negado a presença de uma disciplina específica sobre o tema. Segundo os 199 alunos, diversas disciplinas mostraram-se envolvidas com essa oferta nos cursos pesquisados. A maior parte dos alunos $(152,76,4 \%)$ identificou entre 1 a 3 disciplinas que abordaram a sexualidade, e somente 4,5\% (9) deles afirmaram a presença do tema em mais de 5 disciplinas. A sexualidade foi ofertada por até 5 docentes em todo o curso, segundo $89,4 \%$ (178) dos alunos.

Os alunos caracterizaram as disciplinas envolvidas com o ensino da sexualidade como majoritariamente obrigatórias (186; 93,5\%), localizadas no $3^{\circ}$ e $4^{\circ}$ ano dos cursos (189; 95\%) e no ciclo básico (119; 59,8\%). Disciplinas optativas (12; 6,0\%), atividades de extensão $(2 ; 1 \%)$ e pesquisa $(7 ; 3,5 \%)$ foram pouco citadas pelos alunos.A Ginecologia foi reconhecida por 183 alunos (91,9\%) como aquela que mais debateu o assunto, em todas as escolas médicas pesquisadas. A seguir, foram listadas a Psiquiatria (110; 55,3\%), a Psicologia Médica $(61 ; 30,6 \%)$ e a Urologia $(48 ; 24,1 \%)$. A sexualidade foi abordada, principalmente, em até 6 horas por disciplina $(99 ; 49,7 \%)$.

\section{Atividades Didáticas Utilizadas}

Dos 209 alunos que responderam ao questionário, 200 (95,7\%) discriminaram as atividades didáticas. Para 99\% (198/200) dos alunos, as atividades expositivas foram as mais utilizadas, prevalecendo sobre as práticas $(156 / 200 ; 78,0 \%)$. A aula teórica foi a atividade expositiva mais frequentemente escolhida pelos docentes, seja de forma isolada $(122 / 198 ; 61,6 \%)$ ou associada a seminários, grupos de discussão ou filmes (58/198; $29,3 \%$ ). Por sua vez, as atividades práticas foram desenvolvidas predominantemente em sala de aula $(68 / 156 ; 43,6 \%)$, seguidas de atividades ambulatoriais $(49 / 156 ; 31,4 \%)$. Segundo $22,4 \%$ (35/156) dos alunos, foram realizadas atividades práticas múltiplas, que incluíram atividades em sala de aula, atendimentos a pacientes em ambulatórios e enfermarias.

\section{Título das Aulas Ministradas}

Do total de alunos que responderam ao questionário, 203 $(97,1 \%)$ identificaram o tema sexualidade inserido em diversas aulas de várias disciplinas. A sexualidade foi citada como 
tema específico de aula por apenas 8,4\% (17) deles. No entanto, as aulas sobre câncer ginecológico e do trato genital masculino (144; 70,9\%), aborto (137; 67,5\%), prevenção de DSTs e HIV/ Aids $(136 ; 67 \%)$ foram aquelas que o docente mais frequentemente ministrou o assunto. As doenças psiquiátricas foram palco para a inserção de temas sexuais, segundo 93 (45,8\%) alunos. As aulas que associaram a sexualidade a aspectos não patológicos foram menos observadas, como anatomia e fisiologia dos aparelhos genitais femininos e masculinos (121; $59,6 \%)$ e anticoncepção $(70 ; 34,5 \%)$.

\section{Aspectos da Sexualidade Inseridos nas Aulas}

Os aspectos da sexualidade abordados nas aulas ou disciplinas foram informados por $202(96,6 \%)$ alunos e caracterizados como predominantemente clínicos e de doenças associadas ao exercício da sexualidade. Os estudantes relataram as disfunções sexuais e os transtornos da sexualidade como os mais comentados em $84,1 \%$ (170) e $82,7 \%$ (167) das vezes, respectivamente. Quanto aos aspectos eróticos, houve maior destaque para as etapas do ciclo de resposta sexual (180; $89,1 \%$ ) e menor para masturbação, prazer e zonas erógenas $(135 ; 66,8 \%)$. A sexualidade em situações especiais, como durante a adolescência, gestação e terceira idade foi referida por 149 (73,8\%) alunos e, menos frequentemente, a sexualidade forense $(73 ; 36,1 \%)$ e a sexualidade relacionada à deficiência $(4 ; 2,0 \%)$.

No que diz respeito aos aspectos sociais, a violência sexual foi relatada por 70,2\% (142) dos alunos, além da inserção de tópicos que relacionaram a sexualidade a drogas e comportamento de risco $(129 ; 63,8 \%)$. No entanto, nesse contexto de construção social da sexualidade, foram pouco destacados os direitos sexuais e reprodutivos $(82 ; 40,6 \%)$, papéis de gênero, identidade e cultura $(62 ; 30,7 \%)$ e homofobia $(50 ; 24,7 \%)$. Com relação aos aspectos associados à orientação sexual, a heterossexualidade recebeu maior ênfase, segundo 69,3\% (140) dos alunos. A homossexualidade (101; 50,0\%) e a bissexualidade $(77,38,1 \%)$ foram pouco citadas.

\section{Valorização da Sexualidade por Alunos e Docentes}

Segundo os alunos, os docentes que abordaram a sexualidade eram, na maioria, graduados em medicina $(191 ; 95,8 \%)$ e de ambos os sexos $(121,60,8 \%)$. De 204 alunos que responderam sobre as atitudes dos docentes diante de temas sexuais, 167 $(81,9 \%)$ informaram a valorização desses temas em aulas teóricas, práticas e durante o atendimento aos pacientes. No entanto, para $12,7 \%$ (26) deles, os docentes apresentaram atitudes negativas, como expressar comportamentos de vergonha, ofensa ou raiva, desconversar e não saber como agir.
Levando em consideração todo o curso médico, a metade dos alunos (103; 50,5\%) informou que a sexualidade foi valorizada. Para 199 (96,6\%) alunos o ensino da sexualidade é importante para a sua formação profissional. Enquanto para $96,1 \%$ deles (198/201), a oferta de temas sexuais os ajuda a lidar com sua própria sexualidade e a dos outros, a reconhecer a diversidade do comportamento sexual humano, a acolher sem julgar moralmente os pacientes e a valorizar as suas queixas sexuais.

\section{DISCUSSÃO}

Os currículos da graduação em medicina no Brasil são construídos pelas escolas médicas, mas devem seguir as Diretrizes Curriculares Nacionais, que estabelecem a necessidade da formação de médicos generalistas e humanistas. ${ }^{19} \mathrm{O}$ objetivo é formar profissionais para atuar principalmente em equipe multiprofissional na atenção básica, além dos outros níveis de atenção em saúde. As diretrizes ainda incentivam a integração dos conhecimentos ofertados nas disciplinas do currículo, de forma a favorecer o aprendizado interdisciplinar para a garantia da atenção integral em saúde..$^{19,20}$ Diante disso, é importante destacar que os desenhos das políticas públicas de saúde no país demonstram interesse na promoção da saúde sexual e reprodutiva, com inclusão de ações destinadas à população feminina, masculina, adolescente e LGBT., ${ }^{5,21}$ Sendo assim, essas ações abrem um campo de trabalho para médicos capacitados à promoção integral da saúde sexual da população.

Neste estudo, a maioria dos alunos das escolas médicas do Piauí observou que o tema sexualidade foi abordado em várias disciplinas do currículo. Embora essa evidência de oferta multidisciplinar possa sugerir uma inclusão satisfatória da sexualidade nos currículos, os dados coletados não puderam indicar a existência de interdisciplinaridade entre as diversas disciplinas. Nesse sentido, a proposta pedagógica mundial para o ensino da sexualidade defende a sua inserção como um tema vertical nos currículos e recomenda um ensino multi e interdisciplinar, centrado no aluno com problematização de casos clínicos. A oferta da sexualidade deve estar apoiada na aquisição de conhecimentos, no estímulo para reflexão e mudança de atitudes diante de temas sexuais e no treino de habilidades. ${ }^{22}$ As recomendações que norteiam a formação médica no país estão alinhadas com essa proposta pedagógica. ${ }^{19,20}$

Os alunos informaram que a sexualidade foi ofertada principalmente por disciplinas obrigatórias, localizadas no $3^{\mathrm{o}}$ e $4^{\circ}$ ano dos cursos, que representam especialidades médicas como ginecologia, psiquiatria, urologia e também pela psicologia médica. Assim, o ensino da sexualidade ofertado nos cursos avaliados expressa o campo disciplinar de atuação da 
sexologia no Brasil. ${ }^{23}$ Houve escassa inserção da sexualidade em disciplinas optativas, atividades de extensão e pesquisa. A carga horária destinada ao ensino da sexualidade foi pequena (até 6 horas: 47,4\%), quando comparada à afirmação de diversos autores de que menos de 10 horas dedicadas a esse ensino parece ser insuficiente para a aquisição de conhecimentos, mudança de atitudes e treino de habilidades para as questões sexuais. ${ }^{211,24}$ Algumas experiências de inserção de educação sexual nos currículos de escolas médicas americanas foram descritas, com carga horária variando entre 20 a 48 horas, pela oferta de diversas atividades teóricas e práticas. ${ }^{12,16,24}$

As mudanças na formação médica instituídas pelos Ministérios da Educação e Saúde enfatizam o aprendizado prático e a integração dos estudantes com a população, em cenários variados de aprendizagem. ${ }^{19,20}$ Nesse sentido, os alunos piauienses relataram uma pequena diversificação dos cenários para o aprendizado em saúde sexual em todos os quatro cursos pesquisados. As atividades didáticas utilizadas para o ensino da sexualidade foram predominantemente expositivas, através de aulas teóricas. Além disso, as aulas práticas tiveram pequena contextualização clínica, com poucas oportunidades de atendimento a pacientes. Esses dados ficaram evidentes quando apenas 20 a 30\% dos alunos informaram o recurso de atividades múltiplas para ensinar sobre sexualidade, em todas as escolas estudadas.

As bases da educação médica brasileira atual deslocaram as atenções, anteriormente voltadas a um currículo mínimo, em direção à aquisição de aptidões e competências a serem desenvolvidas pelos alunos. Para isso, o docente deve perder o papel central no processo de ensino-aprendizagem e atuar como facilitador dos estudantes na construção do conhecimento e obtenção de habilidades cognitivas, psicomotoras e emocionais para a atenção em saúde. ${ }^{19,20,25}$ Neste estudo, o predomínio de aulas teóricas para abordar a sexualidade e, principalmente, a menor frequência de atendimento clínico, podem ter limitado o aprendizado para o atendimento em situações que envolvem a saúde sexual e reprodutiva. Dessa forma, o desempenho dos docentes pode ter ficado comprometido para facilitar a aquisição de habilidades emocionais pelos estudantes para o atendimento em sexualidade.

Esse dado se assemelha com aqueles de um estudo qualitativo realizado no México e publicado em 2012. O discurso de alunos de medicina sobre os significados associados à sexualidade e suas experiências em abordar o assunto foram analisados. Os alunos comentaram que o ensino da sexualidade ocorreu nas disciplinas de ginecologia, psiquiatria e urologia, com enfoque reprodutivo, de doenças mentais e orgânicas, respectivamente. Além disso, relataram conforto ao lidar com aspectos biológicos da sexualidade, especialmente relacionados ao coito. No entanto, negaram habilidades para abordar temas eróticos, como prazer e, principalmente, para $o$ atendimento em situações de violência sexual e de gênero. Nesses casos, houve o relato a respeito do despreparo emocional, técnico e legal para a assistência, o que pode sugerir uma formação deficiente para a prática profissional. ${ }^{13}$

No presente estudo, os alunos identificaram a sexualidade inserida em aulas variadas. Houve associação majoritária entre sexualidade e doenças orgânicas ou psiquiátricas e menor frequência em aulas sobre anatomia e fisiologia, embora $49,5 \%$ dos alunos tenham informado a oferta de sexualidade em disciplinas básicas. Aulas específicas sobre sexualidade foram muito pouco ofertadas $(8,3 \%$ dos alunos) e também apresentaram títulos que expressam aspectos disfuncionais: transtornos da sexualidade e violência sexual. Embora o instrumento de pesquisa utilizado não contemple entrevista com o docente para conhecer o enfoque da sexualidade ofertado nessas aulas, sabe-se que temas como câncer, aborto, doenças psiquiátricas, DST e Aids podem favorecer uma visão negativa da sexualidade. O prazer sexual, considerado como um reforçador positivo para os comportamentos sexuais, pode não ter sido satisfatoriamente contemplado durante as aulas ofertadas. ${ }^{9,10}$

Percebe-se que o ensino da sexualidade oferecido pelos docentes das escolas médicas piauienses foi realizado por um viés orgânico, biológico e patológico, semelhante ao que foi oferecido aos alunos mexicanos e observado em estudo recentemente publicado. ${ }^{13}$ Essa constatação pode ser percebida pelo título das aulas e pelos aspectos da sexualidade abordados e identificados pela maioria dos alunos. Como exemplo, a disciplina, a aula e o aspecto da sexualidade mais comentados foram, respectivamente, a ginecologia, o câncer genital feminino e as disfunções sexuais. O mesmo aconteceu nas disciplinas de psiquiatria e urologia, com a observação da grande frequência de relatos sobre o ensino da sexualidade em aulas de doenças psiquiátricas, prevenção de DST, HIV/Aids e câncer genital masculino, além do destaque para os transtornos e disfunções sexuais.

Os aspectos da sexualidade mais abordados pelos docentes foram as disfunções e os transtornos sexuais, diretamente relacionados à inserção do ciclo de resposta sexual, embora com menor destaque para o prazer e masturbação. Houve pouco relevo para os temas sobre história sexual da humanidade, papéis de gênero, homofobia, identidade e cultura, que também caracterizam o adoecimento no âmbito sexual. O reconhecimento dos aspectos sociais ocorreu apenas pela ênfase na violência sexual, provavelmente por ser assunto ofertado 
na ginecologia. Contudo, em 2006, uma pesquisa realizada em três maternidades públicas do Rio de Janeiro, local de referência para atendimento a mulheres vítimas de violência sexual, registrou o discurso dos profissionais de saúde sobre a violência contra a mulher. Mesmo após a realização de cursos de capacitação para o atendimento a mulheres vítimas de violência, esses profissionais reproduziram comportamentos sexistas e reducionistas que justificam a violência contra elas. ${ }^{26}$

Nota-se que o olhar social e cultural que oferece significados ao exercício da sexualidade foi pouco abordado nesses cursos, embora a literatura apresente-se rica em afirmar que a sexualidade envolve aspectos biológicos, socioculturais e psicológicos que não deveriam estar dissociados. ${ }^{910,17,18}$ Portanto, não apenas as doenças orgânicas e psíquicas relacionadas à sexualidade dos indivíduos devem ser valorizadas e tratadas. É necessário que as representações sociais e culturais da sexualidade, que dão sentido e reforçam os comportamentos sexuais das pessoas, sejam consideradas no diagnóstico e terapêutica dos problemas sexuais. Essas informações são evidentes nos resultados de uma pesquisa qualitativa com alunos e médicos sobre violência sexual e de gênero sofrida por mulheres, publicada em 2011. Os alunos relataram habilidades apenas para o tratamento das lesões corporais e informaram despreparo para assistência emocional ou abordagem dos aspectos socioculturais da violência sexual. ${ }^{8,18}$

Neste estudo, os direitos sexuais e reprodutivos foram identificados por menos da metade dos alunos, o que ficou evidenciado pela baixa frequência de aula sobre anticoncepção. A heterossexualidade se impôs como o aspecto da orientação sexual mais valorizado pelos docentes. Esse dado destaca a heteronormatividade dominante do ensino médico nas escolas pesquisadas. ${ }^{27}$ A homossexualidade e a bissexualidade, expressões da diversidade sexual humana, receberam pouca atenção, assim como a homofobia. Para muitos autores, o reconhecimento dos direitos sexuais e reprodutivos como valores democráticos significou dar ao tema uma dimensão de cidadania, evidentes em vários marcos da agenda política mundial, assim como nas políticas públicas de saúde no país. ${ }^{15,28}$ No entanto, mesmo após todo o percurso histórico da construção social dos direitos sexuais e reprodutivos, permanecem presentes os mecanismos que dificultam a universalidade nas ações públicas. Em especial, o saber no campo da saúde, detentor do poder de decisão e de julgamento moral em relação àqueles que buscam o atendimento, pode manter uma cultura de repressão, controle, desrespeito e desigualdade social. ${ }^{21,28}$

As influências positivas conferidas ao ensino da sexualidade na vida profissional e percebidas pela maioria dos alunos deste estudo são corroboradas por vários autores. ${ }^{14,15,16,29} \mathrm{~A}$ atitude dos docentes de valorizar a temática sexual é considerada fundamental para que os alunos possam despertar para a importância desse ensino na sua prática profissional. ${ }^{16} \mathrm{Nes}-$ se sentido, as atitudes dos médicos diante de temas sexuais costumam influenciar a qualidade do atendimento prestado, além de desempenhar um papel social na formação de atitudes públicas sobre práticas sexuais da população. ${ }^{11}$ As habilidades para comunicação sobre assuntos sexuais e para a coleta de uma história sexual está diretamente relacionada ao treinamento adequado durante a graduação. ${ }^{14}$ As crenças e valores morais rígidos dos médicos podem constituir obstáculos para uma assistência ética envolvendo a sexualidade. ${ }^{15}$

Para a promoção da saúde sexual, é necessário que os profissionais desenvolvam habilidades de comunicação e sensibilidade para ouvir as queixas sexuais dos pacientes que atendem. As crenças e valores morais dos médicos e estudantes, relacionados especificamente a temas sexuais, podem interferir negativamente na relação médico-paciente e determinar prejuízos no atendimento médico. Além disso, dificuldades no exercício da própria sexualidade por estudantes e médicos são barreiras que dificultam a assistência em questões de saúde sexual. ${ }^{29}$ Uma pesquisa publicada em 2008 e realizada com estudantes de medicina de Botucatu observou crenças relacionadas à sexualidade expressa nos seus discursos. Eles demonstraram maiores conhecimentos a respeito de patologias associadas à sexualidade, expressando preconceitos e crendices a respeito da sexualidade feminina e homossexualidade. As autoras defendem a inserção da sexualidade em espaços de aprendizagem na graduação de medicina visando à melhor formação profissional em saúde sexual. ${ }^{29}$

Aqui se apresenta algumas limitações, dentre elas, o desenho transversal que representa apenas um recorte da realidade, em um determinado período de tempo. Portanto, reavaliações periódicas poderão ser necessárias para observar mudanças na realidade estudada. Além disso, o instrumento de pesquisa utilizado não permite extrapolar os resultados observados para outras IES, localizadas em outras regiões do país. A escolha por entrevistar alunos do final dos cursos, para identificar retrospectivamente os conteúdos em sexualidade abordados, pode ter determinado vieses de informação por erros de memória e, em consequência disso, uma heterogeneidade de respostas a algumas questões.

\section{CONSIDERAÇÕES FINAIS}

Neste estudo, os alunos do internato dos cursos de medicina do Piauí descrevem o ensino da sexualidade de forma multidisciplinar durante toda a graduação, sem, no entanto, o instrumento de pesquisa poder detectar integração entre as 
diversas disciplinas. Os dados coletados revelam ainda que o ensino foi realizado, principalmente, em atividades expositivas teóricas, além de refletir uma visão centrada nos aspectos biológicos e patológicos, com pequeno destaque para a construção social da sexualidade.

Pela importância e impacto da sexualidade na saúde geral dos indivíduos associada à demanda de profissionais capacitados para a promoção da saúde sexual da população, este tema merece maior destaque na formação médica. Assim, este estudo desejou contribuir para a reflexão sobre o ensino da sexualidade nos cursos médicos piauienses, sob a perspectiva da formação profissional, objetivando uma atenção integral para a saúde sexual. Com essa finalidade, a realização de estudos de maior abrangência territorial, com docentes de várias regiões do Brasil, pode auxiliar no conhecimento sobre o ensino médico em sexualidade ofertado no país como um todo.

Uma boa assistência em saúde sexual não pode dispensar o trabalho interdisciplinar de uma equipe multiprofissional treinada para esse fim. Diversas doenças relacionadas a muitas especialidades médicas têm impacto direto sobre a função sexual das pessoas. Dessa forma, propiciar aos alunos uma formação que valorize os múltiplos aspectos da sexualidade humana ajudará a preparar profissionais sensíveis à temática e, possivelmente, mais preparados para trabalhar na interdisciplinaridade para a promoção integral da saúde sexual da população.

A visão organicista e reducionista da sexualidade, a utilização de cenários de prática pouco diversificados, a pequena abordagem de aspectos socioculturais e, ainda, a falta de interdisciplinaridade na oferta do tema representaram aspectos negativos do ensino médico, dentro do universo pesquisado. Dessa forma, embora a percepção dos alunos tenha indicado que houve a oferta de conteúdos em sexualidade nos cursos avaliados, a formação médica no Piauí mostrou-se limitada para responder às diretrizes que norteiam a assistência em saúde sexual e reprodutiva das políticas públicas de saúde.

\section{REFERÊNCIAS}

1. Wagner G. Sexual medicine in the medical curriculum. Int J Androl. 2005;28(suppl. 2):7-8.

2. Obedin-Maliver J, Goldsmith ES, Stewart L, White W, Tran E, Brenman S, et al. Lesbian, gay, bisexual, and transgender-related content in undergraduate medical education. JAMA. 2011;306(9):971-7.

3. Abdo C, Moreira Junior ED, Santos DB, Wroclawski E, Fittipaldi JAS. Percepções e atitudes sobre disfunção erétil entre médicos no Brasil: resultados do projeto Avaliar. Rev Bras Med. 2004;61(9):613-9.
4. Abdo CHN, Oliveira Junior WM. O ginecologista brasileiro frente às queixas sexuais femininas: um estudo preliminar. Rev Bras Med. 2002;59(3):179-86.

5. Brasil. Ministério da Saúde. Política Nacional de Saúde Integral de Lésbicas, Gays, Bissexuais, Travestis e Transexuais [internet]. Brasília; 2010 [acesso em 20 dez. 2012]. Disponível em: http://www.abglt.org.br/docs/PoliticaNacional_SaudeIntegral_LGBT.pdf

6. Mello L, Perilo M, Braz CA, Pedrosa C. Políticas de saúde para lésbicas, gays, bissexuais, travestis e transexuais no Brasil: em busca de universalidade, integralidade e equidade. Sex Salud Soc. 2011;9:7-28.

7. Farias RS, Cavalcanti LF. Atuação diante das situações de aborto legal na perspectiva dos profissionais de saúde do Hospital Municipal Fernando Magalhães. Ciênc Saúde Colet. 2012;17(7):1755-63.

8. Pedrosa CM, Spink MJP. A violência contra mulher no cotidiano dos serviços de saúde: desafios para a formação médica. Saude Soc. 2011;20(1):124-35.

9. World Health Organization. WHO. Measuring sexual health: conceptual and practical considerations and related indicators. 2010 [internet]. [Acesso em $20 \mathrm{dez}$. 2012]. Disponível em: http://whqlibdoc.who.int/hq/2010/who_ rhr_10.12_eng.pdf

10. World Association for Sexual Health. Sexual Health for the Millennium: a declaration and technical document, USA: World Association for Sexual Health; 2008.[internet]. [Acesso em 20 dez. 2012]. Disponível em: http://www. worldsexology.org/sites/default/files/Millennium\%20 Declaration\%20(English).pdf

11. Solursh DS, Ernst JL, Lewis RW, Prisant ML, Mills TM, Solursh LP, et al. The human sexuality education of physicians in North American medical schools. Int J Impot Res. 2003;15(suppl 5);S41-S45

12. Fitz Gerald M, Crowley T, Greenhouse P, Probert C, Horner P.Teaching sexual history taking to medical students and examining it: experience in one medical school and a national survey. Med Educ.2003;37:94-8

13. Salinas-Urbina AA. La confrontación de la sexualidade en la práctica profesional de los futuros médicos: la mirada de los pasantes de medicina. CiêncSaúde Colet.[periódico na internet] 2012.[Acesso em 20 dez. 2012]. Disponível em: http:/ / www.cienciaesaudecoletiva.com.br/artigos/artigo_int.php?id_artigo=9922.

14. Shindell AW, Ando KA, Breyer BN, Lue TF, Smith JF. Medical student sexuality: how sexual experience and sexuality training impact U.S. and Canadian medical students' comfort in dealing with patients' sexuality. Acad Med. 2010;85:1321-30. 
15. Riffenburg RS, Strassman HD. A curriculum in sexual education for medical students. J Med Educ. 1967;42(11):1031-6.

16. Leiblum SR. An established medical school human sexuality curriculum: description and evaluation. Sex Relation Ther. 2001;16(1):59-70.

17. Abdo CHN. Sexualidade humana e seus transtornos. $2^{\text {a }}$ ed.São Paulo: Lemos; 2000.

18. Cavalcanti R, Cavalcanti M. Tratamento clínico das inadequações sexuais. $3^{\underline{a}}$ ed. São Paulo: Roca; 2006.

19. Brasil. Ministério da Educação. Resolução CNE/CSE no 4/2001. Diretrizes Curriculares Nacionais do curso de graduação em Medicina. Conselho Nacional de Educação. [internet]. Brasília: Câmara de Educação Superior. 2001. [acesso em 20 dez. 2012]. Disponível em: http://portal. mec.gov.br/cne/arquivos/pdf/CES04.pdf

20. Brasil. Ministério da Saúde. Programa Nacional de Reorientação da Formação Profissional em Saúde (Pró-Saúde): Objetivos, Implementação e Desenvolvimento Potencial [internet]. Brasília; 2007 [Acesso em 20 dez. 2012]. Disponível em: http://bvsms.saude.gov.br/bvs/ publicacoes/07_0323_M.pdf.

21. Brasil. Ministério da Saúde. Direitos sexuais e Direitos Reprodutivos: uma prioridade do governo [internet]. Brasília; 2005 [acesso em 20 dez. 2012]. Disponível em: http:/ / bvsms.saude.gov.br/bvs/publicacoes/cartilha_direitos_ sexuais_reprodutivos.pdf.

22. Parish SJ, Rubio-Aurioles E. Education in sexual medicine: proceedings from the International Consultation in Sexual Medicine, 2009. J Sex Med 2010;7(10):3305-14.

23. Russo JA, Rohden F, Torres I, Faro L. O campo da sexologia no Brasil: constituição e institucionalização. Physis. 2009;19(3)617-36.

24. Lief HI. Preparing the physician to become a sex counselor and educator. Pediatr Clin North Am. 1969;16(2):447-58.
25. Pontes LA, Rego S, Silva Júnior AG. Saber e prática docente na transformação do ensino médico. Rev Bras Educ Med. 2006;30(2):66-75.

26. Cavalcanti LF, Gomes R, Minayo MCS. Representações sociais de profissionais de saúde sobre violência sexual contra a mulher: estudo em três maternidades públicas municipais do Rio de Janeiro, Brasil. Cad Saúde Pública. 2006

27. Lionço T. Que direito à saúde para a população GLBT? Considerando direitos humanos, sexuais e reprodutivos em busca da integralidade e da equidade. Saude Soc. 2008;17(2):11-21.

28. Ávila MB. Direitos sexuais e reprodutivos: desafios para as políticas de saúde. Cad Saúde Pública 2003;19(suppl. 2):S5465-S9.

29. Lima MCP, Cerqueira ATAR. Crenças sobre sexualidade entre estudantes de medicina: uma comparação entre gêneros. Rev Bras Educ Med. 2008;32(1):49-55.

\section{CONTRIBUIÇÃO DOS AUTORES}

Andréa Cronemberger Rufino e Alberto Pereira Madeiro participaram da concepção do estudo, análise, interpretação dos dados e redação do artigo. Manoel João Batista Castello Girão participou da concepção do estudo, redação e revisão final do artigo.

\section{CONFLITO DE INTERESSES}

Declarou não haver.

\section{ENDEREÇO PARA CORRESPONDÊNCIA}

Andréa Cronemberger Rufino

Av Coronel Costa Araújo, 3033

Horto Florestal - Teresina

CEP. 64052-820 PI

E-mail: andreacrufino@gmail.com 